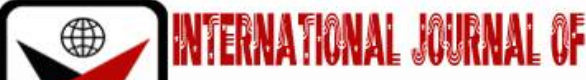

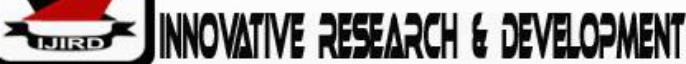

ISSN 2278 - 0211 (Online)

\section{Enhancement Strategies for Effective Adoption of Dairy Farming Technologies by Rural Women in Khwisero, Kakamega County, Kenya}

\begin{tabular}{c} 
Maindi Lilian Janetrix \\
Consultant, Kenya National Vaccine and Immunization Program, New Horizon, USA \\
Dr. Leah Wanjama \\
Lecturer, Department of Sociology Gender and Development Studies, \\
Kenyatta University, Kenya \\
Dr. Pauline Kamau \\
Lecturer Institute of Anthropology Gender and African Studies, \\
University of Nairobi, Kenya \\
Dr. Wanjiru P. Kinuva \\
Lecturer, School of Education and Social Science, KAG EAST University, Kenya \\
\hline
\end{tabular}

\begin{abstract}
:
The use of appropriate technologies by rural women dairy farmers would help increase dairy production globally to meet the growing demand for milk and dairy products. This envisioned growth for the industry will not be realized without the adoption and appropriate use of dairy technologies by rural women dairy farmers. Yet the adoption rate has remained low. The study from which the article is based was conducted in Khwisero sub-county, Kakamega County in Kenya in 2017 with an aim to determining better strategies for the adoption of dairy technologies in the location of study. Random sampling was used to sample location and sub-location and to select 72 respondents from the target of 720.The suggested strategies included improvement on frequency of trainings and methods used and the use of an integrated-multisectoral training approach with information packaged so as to promote gender equity and equality in adoption. In addition, a greater use of more women mentors and rewarding of women role model in dairy farming were recommended. Other proposals included strengthening the capacities of extension officers, understanding gender needs, motivating women to invest in dairy technologies as well as NGOs and the County Government developing a unified approach to disseminate of information on dairy technologies. In other words, the employment of integrated, multisectoral and multifaceted approaches that are inclusive of both men and women were strongly encouraged in the enhancement of dairy farming technologies adoption in the study area.
\end{abstract}

Keywords: Appropriate dairy technologies, strategies for enhancing dairy technologies, rural women dairy farmers, integrated multisectoral approaches, inclusivity of gender in dairy technologies

\section{Introduction}

The United Nations General Assembly 2030 Agenda set out 17 Sustainable Development Goals (SDGs). The SDG 1 and 2 envisions strategy of eradicating extreme hunger and poverty, (UNESCO 2015). One way of meeting these goals is by growing the dairy industry. The use of appropriate technologies by rural women dairy farmers could help increase dairy production globally to meet the growing demand for milk and dairy products. This envisioned growth for the industry will not be realized without the adoption and appropriate use of dairy technologies.

According to Abel, Osoro and Getabu (2015) dairy farming technologies have several benefits namely, excellent reproduction potential, faster growth rate and higher yields for both dairy animals and fodders, and improvement of household welfare. Consequently, dairy technologies can mitigate climate change across the world (UNESCO, 2015). This can be achieved through proper utilization and maximization of related farm resources. Besides, the planting of fodder trees is an effect climate change intervention as well. Despite these obvious benefits however adoption of such technologies by rural women in Sub Sahara Africa was still wanting.

According to Mohamed et al. (2004) developed countries recorded immense growth in the dairy industry and income stability at house hold level on account of gender balance and equity in adoption of dairy farming technologies. Aditya (2010) also observed that commitment by rural women to adopt dairy farming technologies in the United States led to owning fewer cows, increased milk production per cow, and reduced pressure on available family resource inputs. This is not the case in Africa. King (2006) found that milk production in Africa had not kept pace with the growing population and added that there still existed significant levels of traditional dairy production. This might be a result of inequality in adoption and effective use of dairy technologies. Accordingly, Tebug et al. (2010) suggested that dairy farming technologies adoption by rural women was 
instrumental in increasing productivity and household income. They however, added that this adoption was slow- paced and low; adversely affecting rural women households practising subsistence dairy farming in Africa.

Wanjala and Njehia (2014) posit that the increase in dairy production in the East African highlands was notable; with an estimated 3 million subsistence dairy farmers. This growth was attributable to the meagre improvement in dairy farming technologies adoption by rural women dairy farmers in this region. For example, in Uganda, Kaaya et al. (2008) contend that women in groups eagerly adopted dairy farming technologies than at household level. In Tanzania, Balija (2014) found that the majority of rural women groups in Arumeru District adopted improved fodder and pasture varieties. This trend in dairy production notwithstanding, the disparities and biases in adoption of dairy technologies among rural women led to unsustainable dairy production in the region.

In Kenya, a study by Wakhungu and Kangethe (2008) established that the dairy sector played a critical role in the livelihood of many Kenyans. The study also established that the industry contributed 4.5\% of total Gross Domestic Product (GDP), making Kenya one of the largest producers of milk in East and Sub-Sahara Africa. On other hand, Gitonga (2014) noted that rural women in Kiambu, Nyandarua and UasinGishu counties had positively adopted dairy farming technologies. He further observed that those counties had increased numbers of milk collection centers, milk bars and processing factories, created jobs for youth and established support businesses in feeds and agro -veterinary supplies. It is apparent however, that these improvements in dairy production were not equally spread across all counties. In other words, there was uneven adoption of dairy farming technologies among rural women dairy farmers.

\section{Enhancement Strategies for Adoption of Dairy Farming Technologies by Rural women}

There are varied study findings on strategies to enhance adoption of dairy farming technologies. In one study, Mekonnen et al. (2009) established that development and implementation of policies in dairy farming programmes was predominantly exclusive in pushing for adoption. This was after a clear understanding of the factors affecting adoption of dairy farming technologies.

A study by Anuonka et al. (2015) also established that engaging rural women in identifying features of dairy technologies that respond to their realities, opportunities and constraints was crucial. The researchers further observed that engaging with norms and assumptions that affected women's articulation of demand for adoption of dairy farming technologies would be an apt strategy for boosting adoption. Interplay on cultural norms and values might affect the value proposition of dairy farming technologies. Exploring this, could help understand the motivations behind adoption of dairy technologies, and help inform dairy development agencies to direct their effort to those technologies that could cause lesser conflict with traditional cultural practices. This can be a suitable strategy to promote more rural women's acceptance and sustainable use of dairy farming technologies.

According to Kelsey's (2013) study in developing countries on market inefficiencies and the adoption of dairy farming technologies in East Africa commended the following strategies. First, is the systematic evaluation of the true profitability of technologies coupled with provision of low interest rate loans to empower rural women to secure property rights. Secondly, is to ensure efficient markets for dairy produce and products. Additionally, is to have suitable approaches for addressing underlying constraints to adoption. An integration of these strategies would benefit the enhancement of adoption of dairy farming technologies.

\section{Methodology}

The study from which the article is written employed a descriptive survey research design to collect both qualitative and quantitative data from Khwisero sub-county, Kakamega County in Kenya. The study aimed to establish the determinants of the adoption of dairy technologies in the location of study. The target population for the study comprised all women who were dairy farmers in the cooperative group in Kwisero. Random sampling was used to sample location and sub-location and to select 72 respondents from the target of 720 . The study used different instruments to collect both primary and secondary data. These included questionnaires, key informant interview guides, focus group discussions guides and an observation checklist.

\section{Results and Analysis}

\begin{tabular}{|c|c|c|}
\hline Strategy to Enhance Adoption of Dairy Farming Technologies & Frequency & Percentage \\
\hline Improvement on training methods and frequency & 18 & 40 \\
\hline Promote more women mentors in rural areas & 15 & 33 \\
\hline County Government and NGOs support & 12 & 27 \\
\hline Total & 45 & 100 \\
\hline
\end{tabular}

Table 1: Strategies to Enhance Adoption of Dairy Farming Technologies

The results on Table 1 depicts $40 \%$ of the respondents with the opinion that improvement on training methods and frequency of training as a mechanism to enhance adoption; while 33\% suggested the need to promote more women as mentors. On the other hand, $27 \%$ indicated support from the County Government and NGOs as a way to enhance adoption of dairy farming technologies. Whereas, information was a key to rural women making sound decision in adoption, there might be no guaranteed procedure to ensure transfer of technological knowledge. The question on training methods as a strategy to enhance adoption of dairy farming technologies was asked and different interviews with key informants yielded varied answers.

What came out of one interview was that information packaging to promote gender equity in access and utilization of resources should be included in future trainings. This would promote household equality; enhance inclusivity of both women and men in decision making as well as encourage allocation of household resources in dairy farming technologies adoption. It is therefore crucial that implementers put into account gender-based selection criteria that will enable both women and men access information and awareness of gender implication in adoption.

In another interview, there was a question seeking information on whether training and demonstration farms were 
available in each sub division. In response, a key informant confirmed availability and accessibility of training centers at no costs to the women farmers. He however noted that to enhance future adoption, dairy development agencies in their intervention should explore use of integrated, systematic participatory methodologies; to diagnose socially constructed norms and their applicability in dairy technology trainings. The implementers should ensure the access of such trainings to all farmers through related field days organized in villages and Dairy Farmers Co- operative society centers. Exposure field visits; paired with county, national and international exhibitions were also recommended by participants. Consequently, implementers could embrace use of integrated trainings with professionals drawn from different backgrounds in extension, for instance, agribusiness, sociology, gender and development. All these can enrich rural women knowledge on dairy farming technologies and provide encouragement and social guidance to adopt. The suggested measures canbe anchored in all-inclusive gender framework of training to ease household decisions and foster more adoption of dairy farming technologies.

FGD participants suggested the promotion of more women mentors. However, a key informant stated that the use of women mentors was regarded as a biased strategy. He suggested that gender sensitization training initiatives for all extension personnel were essential. This would aid in navigating perception change within male dominated extension, research bureaucracies and donor agencies more than would women mentorship. Conversely, an extension officer endorsed development of specialized gender training materials such as posters and designing a method for gender analysis aimed at challenging sociocultural bottlenecks to adoption of dairy farming technologies. From the sentiments, there was a need for integrated training approaches that gradually enveloped the ingrained traditional sex differences in roles and responsibilities as a strategy to enhance adoption of dairy farming technologies by rural women dairy farmers in study area. This can be done in short and long duration training programmes for both men and women on implication of socio-cultural norms in adoption.

Another key informant brought out different views on the role of the County Government and NGOs support as a strategy to enhance adoption and sustainability of technologies. In one interview, a key informant suggested that the County Government and NGOs as implementers needed to dedicate time and connect with local administrators. This is in consideration to the role played by local administrator in most rural areas as family mediators, handle varying societal roles and acting as opinion leaders to influences decisions in community. Key informant recommended gender need-based assessment through local administrators for the understanding of community structures and infrastructure requirement for successful implementation of dairy farming technologies. In addition, stated that gender need-based assessment could be done through formal commitment to develop a culture that builds respect, inclusiveness, promote project diversity and embraces men and women uniqueness's in adoption. The suggested strategies might be interpreted as a path to aid implementers to clearly understand the gender dynamics and structures in place for dairy farming technologies adoption.

Another key informant advised that the County Government be proactive in strengthening existing extension services and the building capacity of extension personnel on gender issues in dairy farming technology trainings; as a strategy to ensure equal participation in adoption. Further, adoption should be made a product of access to technical know-how that is aimed at reducing knowledge gaps and offering support in management of the technologies. The informant said that strengthening existing extension services would require carrying out a comparative analysis of current extension strategies by county and national governments. From the key informant's perspective, this might mean transforming and strengthening a more hands on extension service that would help rural women to deal with escalating changes in dairy farming technologies and improve the adoption rate.

One more key informant stressed that aid in facilitation and donation of dairy farming technologies to rural women should be withdrawn. He suggested that dairy stakeholder ought to pursue for an alternative method that could entice rural women to incur costs and invest in dairy farming technologies as an enterprise. Key informant said;

'In order for rural women to invest in dairy farming technologies, financial knowledge, resource mobilisation and flexible ways to access credit facilities would be a better mechanism for initial a option.'

This statement could be deduced to mean that financial knowledge as a women empowerment strategy would most likely put them in a position to seek financial services for sustainable dairy farming technologies adoption. Dairy Farmers Co-operative Society Manager; who was also a key informant advocated for the County Government to strengthen structures and systems to address challenges on land ownership, and provision of security of tenure. Land in most instances in rural area was communally owned and governed by customary laws of inheritance. It therefore calls for the education of both women and men on the implications of customary laws in respect to land ownership; not only to dairy farming technologies adoption but to the overall household land economic activities. This strategy might in turn encourage investment in dairy farming technologies by rural women.

Another key informant proposed that the County Government should work together with NGOs on creating and using standard operation procedures, create linkage in information flows, and develop collaborative effort to steer dairy farming technologies adoption agenda in the County. The question of this support initiative as a strategy to enhance adoption was put forth during FGDs too. Respondents in FGDs recognized the role played by NGOs and the County Government in facilitation and provision of incentives in dairy farming and suggested inclusion of other food crop technology for immediate and long-term benefits. For sustainable dairy farming technologies' adoption, dairy farmers, NGOs and the County government may require to revisit their primary goals. In addition, in their effort to improve the livelihood of rural women and development, the stakeholders needed to reach a formal agreement on strategies needed. These would be a path to ensure different partners play a more effective role in achieving these goals. During FGDs respondents also settled on promotion of women mentor and rewarding women role models as a mechanism to stimulate effort of others in adoption. It can be concluded that the use of women in mentorship in addition to linking it to the changing gender dynamic structures are strategies that might enhance adoption of dairy farming technologies. In another FGDs, respondent advocated sensitization in the study area on the role of men and women in adoption of technologies using vernacular radio stations. They indicated that the same strategy should also be employed to shed light on customary laws and its implication on dairy farming technologies adoption. The approach can be used to contend with cultural impediment of dairy farming technologies adoption.

In one of the FGDs, preference was put on the use of farmer to farmer training as a candid strategy to enhance adoption; as a pathway that would be compatible with the needs of rural women who had to juggle dairy farming activities with household 
chores. This was observed as an action- based plan geared toward helping future dairy farming technologies stakeholders in putting into consideration gender needs, roles and responsibilities before rolling out programme activities. Other views that emerged from FGDs were for implementers to come up with mechanization technology like small tractors to dig and weed land to reduce demand on labour. Lastly, establishing a normative framework by the County Government and collaborative effort to address gender roles would be considered a more proactive strategy to enhance future adoption of dairy farming technologies among rural women dairy farmers in Kakamega County. This recommendation was in line with Doss (2001) and Odongo(2010) pinions that effective partnerships and collaboration with other interested organizations could be an avenue to generate substantial synergy to accelerate the adoption rate of dairy farming technologies.

\section{Conclusions}

From the study findings, rural women dairy farmers as well as key informants suggested different strategies that would enhance adoption. The strategies included improvement on frequency of trainings and methods used. The second strategy was the use of an integrated-multisectoral training approach with information packaged so as to promote gender equity and equality in adoption. In addition, a greater use of more women mentors and rewarding women role model in dairy farming technologies adoption was foreseen as a strategy to help appreciate women and cultivate improved adoption. Other suggested strategies were strengthening the capacities of extension officers, understanding gender needs, motivating women to invest in dairy technologies as well as NGOs and the County Government developing a unified approach to disseminate of information on dairy technologies. In other words, the employment of integrated, multisect oral and multifaceted approaches that are inclusive of both men and women were strongly encouraged in the enhancement of dairy farming technologies adoption in the study area.

\section{References}

i. Abel, M. Osoro, K. and Getabu, A. (2015). Analysis of Factors influencing Farmers' Adoption of improved Rabbit Production Technologies: A case of Nyamira County, Kenya. Retrieved from www.iosrjournals.org.28.1.2018

ii. Aditya, R. Khanal, and Gillespre, Jeffrey, (2014). Adoption and Productivity of breeding technologies: Evidence from US Dairy Farm. AgriBio Forum, 16(1):53-65.

iii. Anounka, V. and Katrine, D. (2015).Gender Matters in Farm Power.KIT, International Maize and Wheat Improvement Center and Research Program on Maize. Dairy citation on www.kit,nl/gender.

iv. Doss, Cheryl (2001).Designing Agricultural Technology for African Women Farmers: Lessons from 25 Years of Experience. World Development, 29(12), 2075-2092.

v. Gitonga, E. (2014). Effects of Patterns of Adoption of Dairy Farming Technology among Small Scale Farmers.Kiambu: GithunguriDivision.PHD Thesis, University of Nairobi. Kesley, J. B., (2013). Market Inefficiencies and the adoption of Agricultural Technologies in Developing Countries. Literature review, Agricultural technology adoption initiative, JPAL(MIT)-CEGABerkeley.

vi. Kesley, J. B., (2013). Market Inefficiencies and the adoption of Agricultural Technologies in Developing Countries. Literature review, Agricultural technology adoption initiative, J-PAL(MIT)-CEGA Berkeley.

vii. King, J. (2006). Heat Stress and Energy Deficit Constrain Milk Yield and Cow Replacement Rate: Animal Science, 82: Pp. 705 - 716.

viii. Luyombya B.G.P. (2014). Farmers training and its influence on adoption of improved dairy husbandry practices in Arumeru District. http://hdl.handle.net/123456789/464. Accessed June 102016.

ix. Mekonnen, A. (2006). Women' Role on Production, Processing and Marketing of Milk and Milk Products in Delbo Watershed of Wolayta Zone, Ethiopia.MSC Thesis Hawassa Univerity.

x. Mohamed, A. M., Ehui, S. and Yamesrah, A. (2004). Dairy Development in Ethiopia. International Food Policy: Research Institute, pp. $124-135$.

xi. Odongo E. N., Melisa G., Gerrit J. (2010): Sustainable improvement of animal production and health. https//catalogue.nla.gov.au. Accessed 3 May 2016.

xii. Tebug, S.F., Kasulo V. Chikagwa-Malunga, S., Wiedemann, S., Robert, D.J. and Chagunda M.G (2011) Smallholder Dairy Production in Northern Malawi.Production Practices and constraints.

xiii. Wakhungu J. W., Ongandi P. M., Wahome R., G. and Okitoi L., O. (2007). Characteristics of grade dairy cattle owning households in mixed small scale farming systems of Vihiga District. https://www.researchgate.net. Accessed 17 June 2016

xiv. Wanjala O., Njehia B.K., Simon P.(2014). Value chain predictors of milk production on smallholder dairy farms in Western Kenya: A multiple regression analysis. 